\title{
REGULATIONS TO ACCESS THE CERTIFICATE OF SPECIALIST IN CLINICAL ANATOMY
}

\author{
Postgraduate Committee \\ Argentine Association of Clinical Anatomy
}

1) REQUIREMENTS TO ACCESS THE CERTIFICATE OF SPECIALIST (instead all those with longer than 15 years in university teaching may opt by the special regimen):

I) To be graduated from a Health Sciences or Veterinary career for longer than 5 years.

II) To work or have worked in university teaching, in Argentina or foreign countries, in paid or ad-honorem charge, for longer than 5 years.

III) To be a member (active or adherent) of the "Asociación Argentina de Anatomía Clínica" (Argentine Association of Clinical Anatomy), for longer than 5 years, at the moment of opting for the certificate. AAAC Honorary Members may apply for the certificate if they are Active Members too.

IV) To demonstrate interest and participation in Clinical Anatomy activities (according to Jury criteria)

V) To be author or co-author of 10 or more full text published articles related to the speciality, in Journals with external peer-review and indexed in international data bases.

VI) To approve theoretical-practical and English evaluations, which will take place annually.

VII) Procedure: Postulants will register in May and June. Curriculum Vitae will be evaluated in July and August. In
September (in a previous date to the Congress or Meeting) will take place theoretical-practical evaluations. This evaluation will include 3 complexity levels: a) Information, b) Understanding, and c) Problems or clinical cases. The last one will be evaluated in English. Results will be informed as APPROVED or DISAPPROVED.

VIII) Jury's decision will be unappealable. The certification will be granted during each year scientific event of the Asociación Argentina de Anatomía Clínica.

2) THE CERTIFICATION

IX) Certificate types:

a) Specialist in Clinical Anatomy with orientation to Clinical Macroscopic, Surgical and Imaging Anatomy.

b) Specialist in Clinical Anatomy with orientation to Microscopic Anatomy, Embryology and Molecular Biology.

$X)$ Jury: The Jury will be formed by 3 AAAC Active Members, with valid certificate of Specialist and nominated by the Postgraduate Committee. In case it was not possible to complete its constitution under these conditions, a foreign professor will be 
included in the Jury, according the transitory rules.

XI) Certification: The AAAC will provide a Certificate of Specialist valid for 5 years, which should be renewed before the end of this period. Lack in renewing the certificate for 2 years after the validity will require a new certification. New certification won't be available by the special régimen established for profesionals with longer than 15 years in university teaching. Once the period has expired, the certification won't be valid.

XII) Requirements for renewing the certifícate:

a) To prove having been Active Member of the AAAC during the whole period of the certification.

b) To have developed activities which demonstrate interest in Clinical Anatomy.

c) To have published (as author or co-author), at least, 2 (two) full text articles on Clinical Anatomy in Journals with external peer-review and indexed in international data bases during the 5 years period of the certificate validity.

3) REQUIREMENTS OF THE SPECIAL REGIMEN FOR PROFESSIONALS WITH LONGER THAN 15 YEARS IN ANATOMY UNIVERSITY TEACHING:

A) To be university graduate from Health Sciences or Veterinary career

B) To be an Active Member of the Asociación Argentina de Anatomía Clínica for, at least, 5 years. AAAC Honorary Members may postulate for the certificate if they are Active Members too.

C) To be or have been professor, in public or prívate university, in
Argentina or foreign countries, in paid or ad-honorem charge, for longer than 15 years (including pregraduate period).

D) To demonstrate interest and participation in Clinical Anatomy activities.

E) To be author or co-author of 10 (ten) full text articles (not abstracts) of Clinical Anatomy published in Journals with external peer-review and indexed in international data bases.

4) IT WILL BE CONSIDERED AS INTERES AND/OR PARTICIPATION IN CLINICAL ANATOMY ACTIVITIES:
a) To have developed lectures, on different topics, in pre or post- graduate courses associated to the speciality.
b) To attend and participate in Congresses and scientific events of Clinical Anatomy.
c) Only attending won't credit to opt for the certification.

\section{5) TRANSITORY RULES:}

a) At the first call, the Jury will be integrated by foreign professors nominated ad-hoc. If after the first call it wasn't possible to join 3 AAAC active members with specialist certificate, the Jury will be completed with foreign professors specifically nominated for this purpose.

b) Since the first and until the 2022 call (included), it will be accepted to have full text articles of Anatomy, Histology and Embryology in general, if at least 5 (five) of them have clinical orientation. 